\title{
Dense and Overlapping Innervation of Pyramidal Neurons by Chandelier Cells
}

\author{
Melis Inan, ${ }^{1}$ Lidia Blázquez-Llorca, ${ }^{2}$ Angel Merchán-Pérez ${ }^{2,3}$ Stewart A. Anderson, ${ }^{1}$ Javier DeFelipe, ${ }^{2,4}$ \\ and Rafael Yuste ${ }^{5}$ \\ ${ }^{1}$ Department Psychiatry, Weill Cornell Medical College, New York, New York 10065, ${ }^{2}$ Laboratorio Cajal de Circuitos Corticales, Centro de Tecnología \\ Biomédica, and ${ }^{3}$ Departamento de Arquitectura y Tecnología de Sistemas Informáticos, Universidad Politécnica de Madrid, 28223 Madrid, Spain, ${ }^{4}$ Instituto \\ Cajal, Consejo Superior de Investigaciones Científicas, 28002 Madrid, Spain, and ${ }^{5}$ Howard Hughes Medical Institute, Department of Biological Sciences, \\ Columbia University, New York, New York 10027
}

Chandelier (or axo-axonic) cells are a distinct group of GABAergic interneurons that innervate the axon initial segments of pyramidal cells and thus could have an important role controlling the activity of cortical circuits. To understand their connectivity, we labeled upper layers chandelier cells (ChCs) from mouse neocortex with a genetic strategy and studied how their axons contact local populations of pyramidal neurons, using immunohistochemical detection of axon initial segments. We studied ChCs located in the border of layers 1 and 2 from primary somatosensory cortex and found that practically all $\mathrm{ChC}$ axon terminals contact axon initial segments, with an average of three to five boutons per cartridge. By measuring the number of putative GABAergic synapses in initial segments, we estimate that each pyramidal neuron is innervated, on average, by four ChCs. Additionally, each individual ChC contacts 35-50\% of pyramidal neurons within the areas traversed by its axonal arbor, with pockets of very high innervation density. Finally, ChCs have similar innervation patterns at different postnatal ages (P18-P90), with only relatively small lateral expansions of their arbor and increases in the total number of their cartridges during the developmental period analyzed. We conclude that ChCs innervate neighboring pyramidal neurons in a dense and overlapping manner, a connectivity pattern that could enable ChCs to exert a widespread influence on their local circuits.

\section{Introduction}

Neocortical function relies on information processing by intricately wired networks of excitatory glutamatergic and inhibitory GABAergic neurons. Among GABAergic interneuron subtypes, chandelier cells (ChCs; also known as axo-axonic cells) are particularly distinctive (Jones, 1975; Szentágothai, 1975; Woodruff et al., 2010). These "fast-spiking," parvalbumin-expressing interneurons have axonal arbors with short vertically oriented axon terminals, called cartridges. These cartridges target the axon initial segment (AIS) of pyramidal neurons, where action potentials are generated (Somogyi, 1977; Fairén and Valverde, 1980). With synapses placed so strategically, ChCs could be potent modulators of cortical circuits. Recent investigations have suggested that they can depolarize pyramidal cells (Szabadics et al., 2006;

Received Aug. 23, 2012; revised Nov. 4, 2012; accepted Nov. 28, 2012.

Author contributions: M.I., L.B.-L., A.M.-P., S.A.A., J.D., and R.Y. designed research; M.I., L.B.-L., and A.M.-P. performed research; M.I., L.B.-L., A.M.-P., S.A.A., J.D., and R.Y. analyzed data; M.I., L.B.-L., A.M.-P., S.A.A., J.D., and R.Y. wrote the paper.

This work was supported by ARO MURI Grant W911NF-12-1-0594, NEI, NINDS, NIHM, Keck Foundation, and NARSAD. We thank I. Chernyavsky for help with the analysis and members of the three laboratories for help and comments.

Correspondence should be addressed to Rafael Yuste, Department of Biological Sciences, Columbia University, 906 NWC Building, 550 West 120 Street, Box 4822, New York, NY 10027. E-mail: rafaelyuste@columbia.edu.

M. Inan's present address: Department of Neurology and Neuroscience, Weill Cornell Medical College, New York, NY 10065.

S. A. Anderson's present address: Department of Psychiatry, Children's Hospital of Philadelphia and University of Pennsylvania School of Medicine, Philadelphia, PA 19104.

DOI:10.1523/JNEUROSCI.4049-12.2013

Copyright $\odot 2013$ the authors $\quad 0270-6474 / 13 / 331907-08 \$ 15.00 / 0$
Woodruff et al., 2009), leading to an excitatory effect on the circuit (Szabadics et al., 2006; Molnár et al., 2008), although these results are controversial (Glickfeld et al., 2009). Alternatively, they could exert a dual function on the pyramidal neuron, either excitatory or inhibitory, depending on its resting membrane potential (Woodruff et al., 2011).

Importantly, ChCs have been implicated in schizophrenia and epilepsy (Lewis and Anderson, 1995; DeFelipe, 1999; Howard et al., 2005; Fazzari et al., 2010). However, due to their scarcity and their lack of specific markers, few studies have examined functional circuit properties of ChCs (Buhl et al., 1994b; Klausberger et al., 2003; Tamás and Szabadics, 2004; Szabadics et al., 2006; Glickfeld et al., 2009; Xu and Callaway, 2009; Zaitsev et al., 2009; Woodruff et al., 2011). Anatomical studies of ChCs are also infrequent. Although the distribution of $\mathrm{ChC}$ cartridges in different areas of the cortex was reported (Inda et al., 2007, 2008), quantitative reconstructions and analysis of the morphology of $\mathrm{ChC}$ arbors have still been uncommon (Somogyi et al., 1985; Li et al., 1992; Lund and Lewis, 1993; Martínez et al., 1996; Krimer and Goldman-Rakic, 2001).

A direct strategy to study synaptic connectivity is to label individual neurons, trace their axons and examine adjacent presynaptic and postsynaptic appositions. In this study, we reconstructed individual ChCs axonal arbors and their postsynaptic targets, i.e., AISs, using a transgenic mouse line where GFPlabeled ChCs are abundant at the layer $1 / 2$ border of the cortex (Xu et al., 2008; Woodruff et al., 2009). We analyzed isolated ChC arbors immunostained for GFP and AIS markers. Consistent 
with earlier reports (Somogyi et al., 1985; Li et al., 1992; Inda et al., 2008), most ChC cartridges innervate AISs. An individual ChC targets $\sim 35-50 \%$ of neurons within its vicinity. Also, we estimated the total number of boutons forming putative synapses in each AIS and found that, on average, each pyramidal neuron is innervated by approximately four ChCs. Similar innervation patterns are observed throughout development, with only a significant increase in the lateral span of the axonal arbor with age. Thus, ChCs innervate their local neighborhood of pyramidal neurons in a dense, overlapping fashion, providing a potential substrate for effective control of cortical circuits.

\section{Materials and Methods}

Animals. Animal handling and experimentation was done according to $\mathrm{NIH}$ and local Institutional Animal Care and Use Committee guidelines. We used Nkx2.1-Cre::MADM transgenic mice that express GFP in a subset of neocortical interneurons, including ChCs located at upper cortical layers, most frequency in the layer $1 / 2$ border (Xu et al., 2008; Woodruff et al., 2009). Animals of both sexes were used.

Immunofluorescence labeling and arbor reconstruction. For immunohistochemistry studies, P18-P90 mice were perfused intracardially with PBS followed by $4 \%$ paraformaldehyde (PFA) and postfixed in fresh $4 \%$ PFA overnight. Brains were then removed and sectioned in the coronal plane at $50 \mu \mathrm{m}$ on a vibrating microtome. Primary antibodies used for immunofluorescence labeling included chicken anti-GFP (Invitrogen, 1:2000) for the identification of the ChCs soma and processes, and rabbit anti-Ankyring (Santa Cruz Biotechnology, 1:1000) and rabbit antiphospho(Ser32)-IKB $\alpha$ (Cell Signaling Technology, 1:2000) for the detection of AISs. Fluorescent secondary antibodies were labeled with Alexa Fluor 488 and 568 (Invitrogen, 1:500). The nuclear marker DAPI (300 $\mathrm{nM}$ ) was applied together with the secondary antibodies. Sections were first blocked with 5\% heat-inactivated goat serum in $0.1 \%$ PBST (PBS with $0.1 \%$ Triton) for $1 \mathrm{~h}$, at room temperature. They were then incubated in blocking solution containing primary antibodies overnight at $4^{\circ} \mathrm{C}$. Then they were washed in $0.1 \%$ PBST six times for $10 \mathrm{~min}$ followed by corresponding secondary immunolabeling for $2 \mathrm{~h}$ at room temperature. Sections were then washed three times for $10 \mathrm{~min}$ and mounted with ProLong Gold Antifade reagent (Invitrogen). ChCs in somatosensory cortex, which were physically isolated from other GFP + cells or processes were chosen by epifluorescence microscopy using a $20 \times$ objective. Montages were done using Photoshop. Chandelier arbors were reconstructed with $100 \times$ oil-immersion objective using Neurolucida (Microbrightfield). Marker analysis for the boutons and Sholl analysis were performed using the Neuroexplorer (Microbrightfield). A cartridge was defined to be composed at least of two or more GFP + boutons, lined up vertically and connected with a thin axonal process. Cartridges in contact with AISs were marked while the reconstruction of the chandelier arbor was carried out. In addition to reconstructing the cartridges and marking the number of boutons, AISs were also reconstructed only at planes where at least one cartridge was present. Therefore, AISs at $z$-planes where no cartridges were detected were not included in the reconstructions. For "maximum hull" analysis, the volume of the $\mathrm{ChC}$ arbor was defined as the maximum $x, y$, and $z$ position where a cartridge was detected. "Convex hull" analysis was performed by redefining the $\mathrm{ChC}$ arbor volume by drawing a line that connects the outermost cartridges at each $x$ and $y$ position and including only the AISs within this polygonal-shaped arbor.

To analyze the overlapping innervation of $\mathrm{ChC}$, sections were double stained with a mixture of two primary antibodies: rabbit anti-Vesicular GABA Transporter (VGAT) (1:2000, Synaptic Systems) and mouse antiAnkyrin G (1:100, Neuromab). Free-floating sections were incubated overnight at $4^{\circ} \mathrm{C}$ in a solution containing the primary antibodies and then for $2 \mathrm{~h}$ at room temperature with an Alexa Fluor-conjugated goat antirabbit 594 antibody and an Alexa Fluor-conjugated goat anti-mouse 647 antibody (1:1000, Invitrogen). Thereafter, the sections were washed and mounted with ProLong Gold Antifade Reagent (Invitrogen Corporation), and examined on a Zeiss LSM 710 confocal laser scanning system. Fluorescence of GFP, and Alexa Fluor 594 and 647 were recorded through separate channels. ChCs isolated from any other GFP + cells or processes were detected in somatosensory cortex by epifluorescence microscopy using a $20 \times$ objective. A $63 \times 1.40$ numerical aperture oilimmersion lens was used to take images of the $\mathrm{ChC}$ axonal arbor. Image stacks consisted of 18-49 optical sections with step size of $0.38 \mu \mathrm{m}$. Reconstruct Software 1.1.0.0 (Fiala, 2005) was used to reconstruct the AISs innervated by GFP+ cartridges and VGAT immunostained buttons.

Statistics. We used one-way ANOVA to compare three different ages for the different parameters analyzed. Next, we used Student's $t$ test to compare two ages for parametric values such as total number of cartridges, total number of AISs, and number of cartridges with a certain number of boutons. For nonparametric values calculated in percentages, such as the percentage of cartridges apposing an AIS and the percentage of AISs apposed by a cartridge, we performed the Mann-Whitney rank sum test, a nonparametric test where the medians are compared.

\section{Results}

In this study, we sought to understand how ChCs connect to their postsynaptic targets. Since ChCs are relatively infrequent in cortical circuits, we used Nkx2.1-Cre::MADM transgenic mice, in which ChCs located in neocortical upper layers can be readily found (Xu et al., 2008; Woodruff et al., 2009; see also Taniguchi et al., 2012). We focused exclusively on this sample of neocortical ChCs in the somatosensory cortex, which belong to a homogeneous morphological and electrophysiological population (Woodruff et al., 2011). With these ChCs, we performed studies of their output connectivity, using immunohistochemical detection of their connections with local AISs of pyramidal cells.

\section{Identification and analysis of $\mathrm{ChC}$ cartridges}

To characterize how ChCs contact their local synaptic targets, we used coronal sections from somatosensory cortex of Nkx2.1-Cre::MADM mice from three different ages (P18, P30, and P90; Fig. 1). ChCs were immunolabeled for GFP (Fig. 1, green) and were identified by their distinctive morphologies. ChCs that were isolated from any other GFP cell or processes were selected, and their axonal arbors reconstructed in 3D $(n=6$ per age). ChC cartridges were easily identified as short, vertical rows of GFP + boutons and were defined for further analysis by having at least two or more boutons lined up vertically and connected by a thin axonal process (Fig. 1, bottom, green lines). Cartridges were located at an average vertical distance of $360 \pm 18$ $\mu \mathrm{m}$ from the parent soma, ranging from 236 to $457 \mu \mathrm{m}$, and an average horizontal distance of $241 \pm 14 \mu \mathrm{m}$, ranging from 134 to $346 \mu \mathrm{m}(n=18)$. Analyses of boutons per cartridge revealed that $78 \%$ of all cartridges had three to five boutons $(78.3 \pm 2.9, n=$ 18; Fig. 2A). Since axonal boutons represent putative synapses, these results suggest that the majority of ChCs form three to five axo-axonic synapses per cartridge. The distribution of cartridges within the chandelier arbor was examined by Sholl analysis from the somatic position (see Materials and Methods). The distribution of cartridges varied with increasing distance from the $\mathrm{ChC}$ soma, with the majority of them (73\%) located within 60-150 $\mu \mathrm{m}$ from the cell body, in layer $2 / 3$ (Fig. $2 B$ ). This suggests that the majority of $\mathrm{ChC}$ axon terminals innervate AISs quite locally. A convex hull Sholl analysis of the distribution of AISs (see Materials and Methods for more details) revealed a bell-shaped curve matching the distribution of cartridges (Fig. 2C). Therefore, within the axonal arbor of a $\mathrm{ChC}$, cartridges are located in the same proportion as available AIS targets, as if they targeted them without selectivity. 

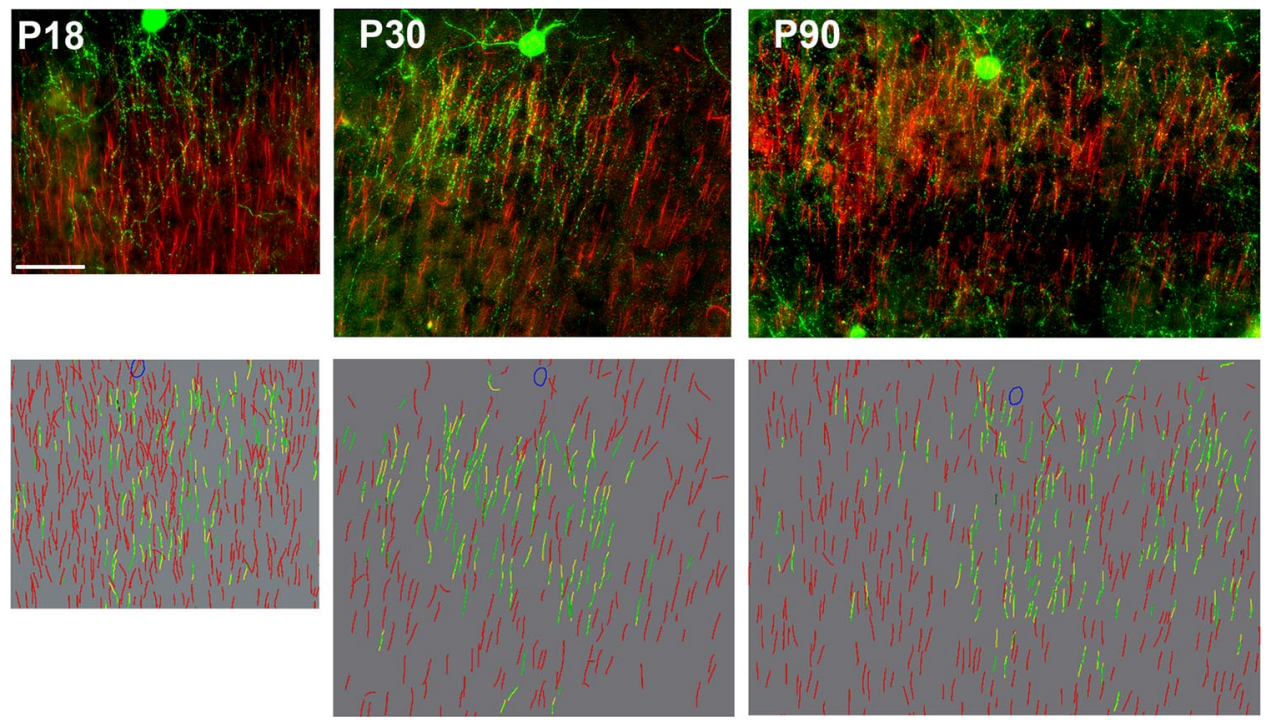

Figure 1. Immunocytochemical detection of ChC axo-axonic connections. Innervation of AlSs by ChC cartridges at different ages. Top, z-projection images of a complete ChC arbor (green, GFP) and AISs (red, AnkyrinG and PIkB immunolabeling) from Nkx2.1-Cre::Madm mice at P18, P30, and P90. Bottom, Projection of 3 D reconstructions of the ChC arbors. Green represents cartridges, yellow represents an AIS apposed by a cartridge, and red represents AlSs that are not apposed by a cartridge. Scale bar, $50 \mu \mathrm{m}$.
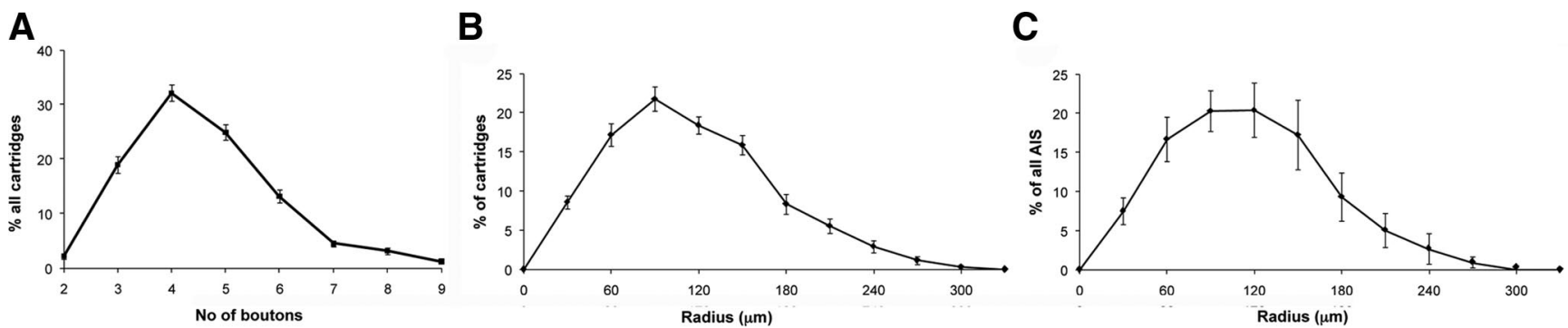

Figure 2. Morphological properties of $\mathrm{ChC}$ arbors. $A$, Number of boutons per cartridge. The majority of the cartridges were found to contain three to five boutons. $B, C$, Distribution of cartridges $(\boldsymbol{B})$ and AISs $(\boldsymbol{C})$ within the ChC arbors examined using Sholl analysis. The cell body is located at the center (radius $=0 \mu \mathrm{m}$ ), and the percentage of cartridges or AlSs is determined at each radial ring around the cell body at $30 \mu \mathrm{m}$ intervals. No significant differences were found for the percentage distributions of cartridges and AISs at different ages, and data from all ages are combined ( $n=18$, 6 cells per each age).

\section{Innervation of AISs by ChC cartridges}

We used immunostaining for two markers (Ankyrin $G$ and Phospho-IKB $\alpha$, red) to detect AISs (Fig. 1, top). AISs were easily identified by their distinct "eyelash" shape and were found throughout layer 2/3. AISs closer to the labeled $\mathrm{ChC}$ soma were often found to be in contact with a cartridge (Figs. 1 bottom, yellow lines, $3 A$ ). These contacts were confirmed at $100 \times$ magnification and were marked in the reconstructions of the chandelier arbor (Figs. 1, bottom, yellow vs red AISs, 3A). On average, $86 \%$ of all cartridges within a radius of $60-150 \mu \mathrm{m}$ from the $\mathrm{ChC}$ body were found to contact an AIS, confirming that most ChCs selectively target AISs (Somogyi, 1977; Fairén and Valverde, 1980). Sholl analysis was then used to examine the distribution of these appositions within each chandelier arbor to analyze what percentage of AISs within the axonal territory of a given ChC was innervated. The percentage of cartridges in contact with an AIS was high and varied between $73 \%$ and $90 \%$ at any radius analyzed up to $210 \mu \mathrm{m}$. On average, the extent of cartridges in contact with AISs was $321 \pm 17 \mu \mathrm{m}$ on the $x$-axis and $233 \pm 20 \mu \mathrm{m}$ on the $y$-axis $(n=18)$. The distribution of these cartridges was initially low and peaked, and stayed constant at $30-210 \mu \mathrm{m}$ and then decreased monotonically until the end of the axonal arbor (Fig. $3 B$ ). This reduction was observed because different chandelier cells varied in the extent of the radius of their arbors, and there- fore the reduction is due to the absence of cartridges at larger radii for certain cells.

We then examined how specifically chandelier terminals target pyramidal neurons. To do so, we calculated the percentage of AISs contacted by a cartridge within the chandelier arbor. For this analysis, it is important to define the territory occupied by the ChC's axon arbor. We first analyzed the data counting all the AISs located within the maximum $x$ and $y$ cartridge coordinates but only in $z$-planes where a cartridge was present (maximum AIS analysis). A more strict criterion to estimate the number of AISs potentially innervated by the $\mathrm{ChC}$ axon was acquired by the cartridge convex hull analysis. In this analysis, the $\mathrm{ChC}$ arbor region is defined as the territory located inside the perimeter that connects the outermost cartridges in the z-projection of the reconstructions, thus including only AISs within this polygonalshaped arbor. Using these criteria, Sholl analysis revealed that on average $30 \pm 3 \%$ (maximum analysis) or $44 \pm 2 \%$ (convex hull) of all AISs were innervated by a cartridge within $210 \mu \mathrm{m}$ from the chandelier soma (Fig. 3C,D). Since the maximum analysis includes all AISs within the maximum extent of the $x$ - and $y$-axes, a lower percentage for appositions is observed compared with the convex hull analysis.

With the global Sholl analysis, the distribution of the percentage of AISs in contact with cartridges was initially low, peaked at 
A
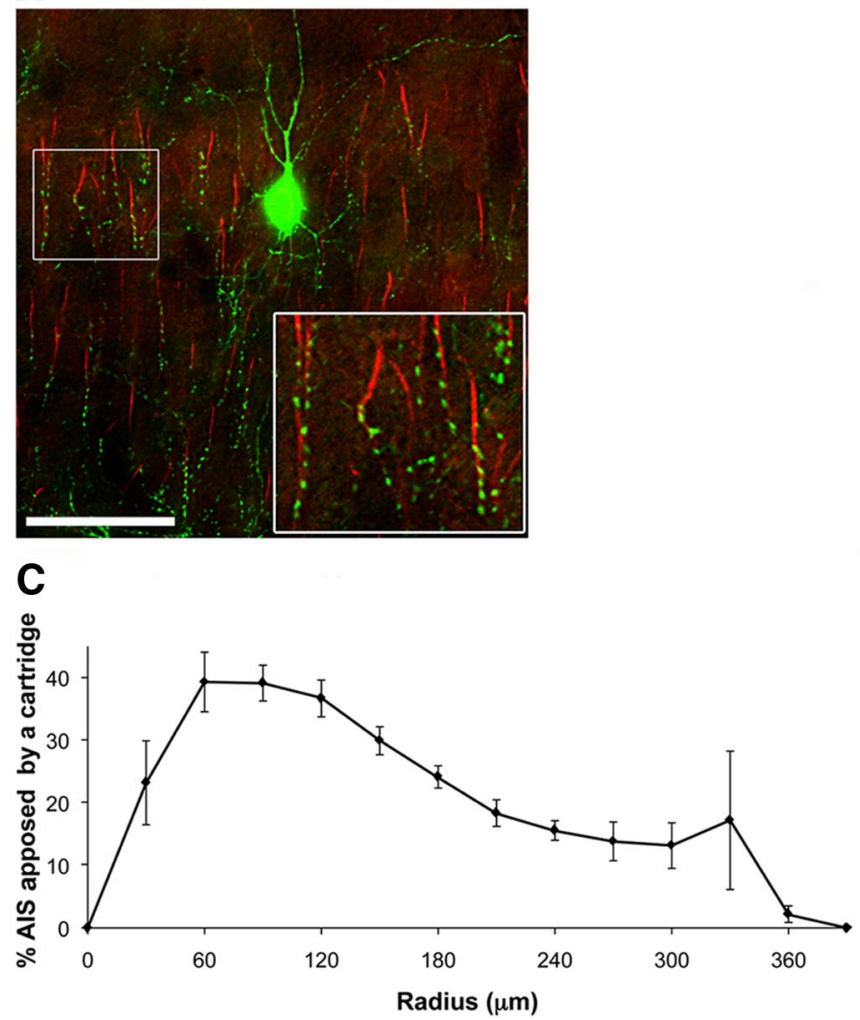

B
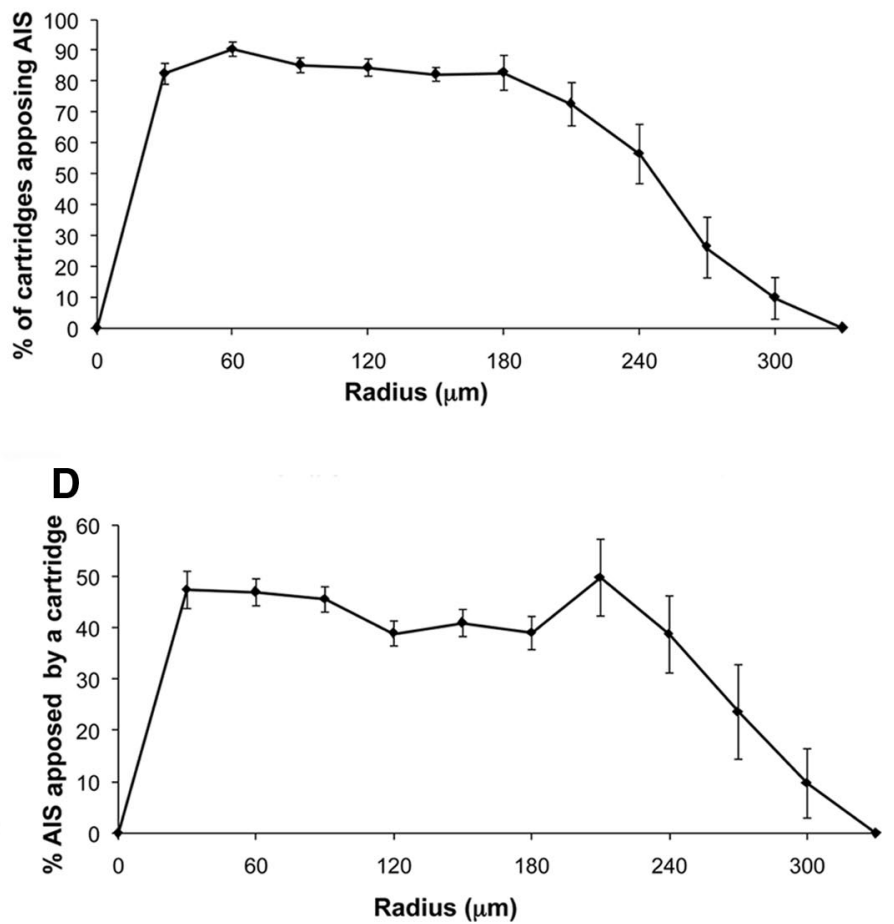

Figure 3. Dense ChC axo-axonic innervation. A, Apposition of cartridges and AISs. Single z-plane image of a ChC cartridges (green) and AISs (red) at P30. Inset, Area with a high density of cartridges, where almost every AIS is apposed by a cartridge. Scale bar, $50 \mu \mathrm{m}$. B, Sholl analysis of percentage of cartridges apposing an AIS within chandelier arbors. Almost every cartridge apposes an AIS. C, Maximum Sholl analysis of the percentage of AISs apposed by a cartridge within a chandelier arbor. The ChC arbor is defined by the maximum $x, y$, and $z$ coordinates. $D$, Convex hull Sholl analysis of the percentage of AISs apposed by a cartridge. The ChC arbor is limited to the coordinates where a cartridge is present.

60-120 $\mu \mathrm{m}$, and then decreased monotonically until the end of the axonal arbor (Fig. $3 C$ ). These data also indicate that the percentage of AISs innervated by cartridges is not different in any area within the $\mathrm{ChC}$ arbor, defined by the concentric rings of the Sholl analysis. With the convex hull analysis, on the other hand, the percentage of AISs apposed to cartridges was $40-50 \%$ throughout the arbor within a radius of $210 \mu \mathrm{m}$ (Fig. 3D). These numbers were similar at each concentric ring around the $\mathrm{ChC}$ somata, suggesting a uniform innervation pattern within a radius of $210 \mu \mathrm{m}$ from the somata. However, in Sholl analysis the axes are combined as one parameter (i.e., the radius) and a different pattern may be observed at individual axes. We explored this by analyzing the distribution of percentage of AISs innervated by cartridges in $x$ - and $y$-axes, but we did not observe any difference in the distribution (data not shown).

Interestingly, qualitative observation of $\mathrm{ChC}$ arbors revealed the presence of high-density areas of cartridges (Fig. $3 A$ ). Closer examination of these high-density areas (Fig. $3 A$, inset) showed that the majority of AISs within these areas are innervated by a cartridge ( 9 of 11 AISs in this example). These observations suggested that the $\mathrm{ChC}$ axon may densely innervate some areas of its arbor.

\section{Development of ChC innervation}

We also explored potential differences present in the $\mathrm{ChC}$ arbor and the cartridge-AIS appositions at three different ages. The typical cartridge morphology was only clearly apparent by P18 and hence we chose to analyze ChCs at P18, P30, and P90 ( $n=6$ per age; Fig. 4). Sholl analysis for the distribution of the percent- age of cartridges revealed no significant differences between ages at a certain radius within $210 \mu \mathrm{m}$ of the ChC somata $(n=6$ for each age group; n.s. with Mann-Whitney rank sum test). However, the percentage of cartridges peaked at $90 \mu \mathrm{m}$ for P18 and $\mathrm{P} 30$, whereas this peak was broader at P90 $(90-150 \mu \mathrm{m})$ and the distribution at P90 was shifted toward larger radii (Fig. 4A). The distribution of AISs also did not differ at the three different ages (Fig. $4 C ; n=6$ for each age group; n.s. with one-way ANOVA). Analysis of the number of boutons per cartridge also did not differ between ages (Fig. $4 B ; n=6$ for each age group; MannWhitney rank sum test), suggesting that the overall percentage of axo-axonic terminals does not change during the developmental period analyzed. In addition, analysis of cartridge-AIS contacts revealed no significant differences in the average percentage of cartridges contacting an AIS (Fig. $4 E ; n=6$ for each age group; comparison of: P18 and P30, $U=13, p=0.485$; P18 and P90, $U=9.5, p=0.18$; P30 and P90, $U=6, p=0.065$ with MannWhitney rank sum test), although there was a trend for a lower percentage of cartridges apposing an AIS at P90 compared with P18 and P30 (median, mean \pm SEM for P18, P30, and P90: 88, $87 \pm 2 ; 84,84 \pm 2$; and $81,81 \pm 0.6$, respectively). The average percentage of AISs contacted by cartridges (Fig. $4 E$ ) within the $\mathrm{ChC}$ arbor at different ages also did not reveal any significant differences $(n=6$ for each age group; P18 vs P30, $U=18, p=1$; $\mathrm{P} 18$ vs $\mathrm{P} 90, U=10, p=0.24$; $\mathrm{P} 30$ vs $\mathrm{P} 90, U=12, p=0.39$ with Mann-Whitney rank sum test).

We were surprised by the lack of stronger developmental modulation in these analyses and examined more closely other potential differences. Although the average density of cartridges 

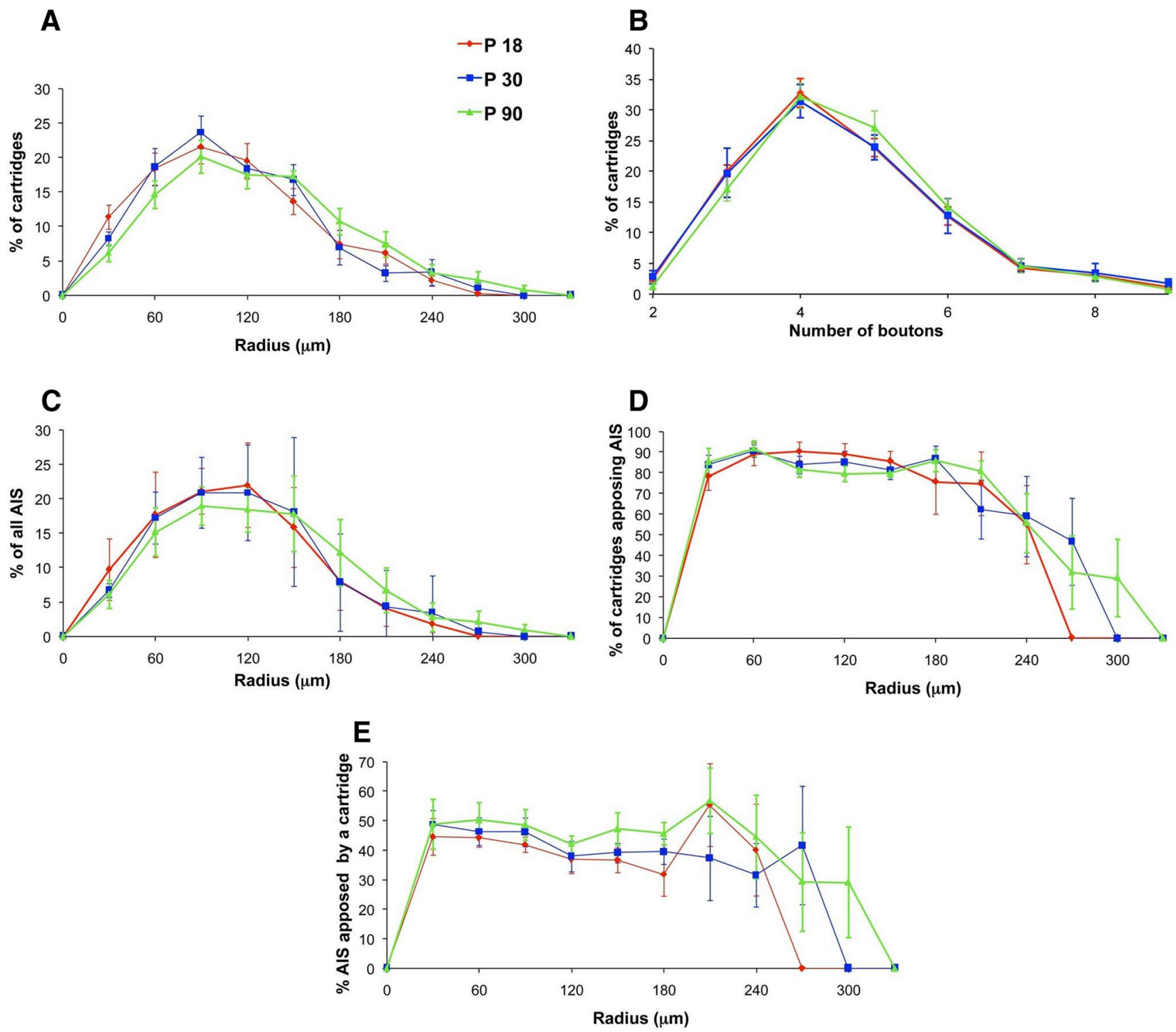

Figure 4. Conservation of ChC innervation patterns at P18, P30, and P90. $A-E$, Convex hull Sholl analysis revealed no significant difference in the distribution of cartridges ( $A$ ), boutons ( $B$ ), AIS $(\boldsymbol{C})$, or appositions $(\boldsymbol{D}, \boldsymbol{E})$ at different ages.

or the AISs did not significantly differ between ages, the total number of cartridges was slightly higher at P30 and P90 compared with P18 (mean \pm SEM: $90 \pm 3,118 \pm 8,109 \pm 2$, respectively, at P18, P30, and P90; $n=6$ per age and $p<0.01$, one-way ANOVA). In addition, analysis along the $x$-axis revealed that the ChC arbor was significantly larger at P90 compared with P18 (mean \pm SEM: $316 \pm 24,356 \pm 33$, and $407 \pm 25 \mu \mathrm{m}$, respectively, at P18, P30 and P90; $n=6$ per age and $p<0.05, t$ test between P18 and P90). Consequently, the region of cartridges in contact with AISs on the $x$-axis was significantly larger at P90 compared with P18 (mean \pm SEM: $312 \pm 23,356 \pm 33$, and $394 \pm 25$, respectively, at P18, P30, and P90; $n=6$ per age; $p<$ $0.05, t$ test, P18 vs P90). Although P30 was not significantly different from P18 or P90, the cartridge and appositions extent on the $x$-axis fell between these two ages. No significant difference was detected for the extent of cartridges (mean \pm SEM: $226 \pm 28$, $220 \pm 19$, and $216 \pm 28 \mu \mathrm{m}$, respectively, at P18, P30, and P90; $n=6$ per age) or the region of cartridges in contact with AISs (mean \pm SEM: $219 \pm 30,210 \pm 17$, and $212 \pm 25 \mu \mathrm{m}$, respec- tively, at P18, P30, and P90; $n=6$ per age) along the $y$-axis between different ages. These data indicate that the $\mathrm{ChC}$ arbor gradually expands laterally throughout development, whereas no significant change occurs on the vertical span of the cortex.

\section{Overlapping innervation of AISs by ChCs}

We finally focused on the question of how many ChCs innervate a single pyramidal neuron. Since we could identify individual ChC terminals, we sought to answer the question by counting the number of terminals that a ChC makes on average on an AIS and comparing that number with the total number of GABA-positive terminals found in the AIS. This approach assumes that all GABAergic terminals in contact with an AIS belong to ChCs. To estimate the number of ChCs that innervate the AISs, we reconstructed 44 GFP-labeled cartridges in contact with AISs stained with Ankyrin G, in sections that were also immunolabeled for the vesicular GABA transporter VGAT (Fig. 5). We made this estimation in the surface of the sections, within the region of better penetration of the immunoreagents. The average number of 
VGAT-immunoreactive (ir) buttons per AIS $( \pm$ SEM $)$ was $15.5 \pm 0.7$, whereas the average number of GFP + buttons per AIS was $4.1 \pm 0.2$. These results indicate that $\sim 3.8 \pm 0.3$ ChCs may participate in the innervation of a given AIS.

\section{Discussion}

Specific ChC innervation of axon initial segments

To understand neocortical function, it is important to examine the functional and anatomical synaptic connectivity within cortical microcircuits. One open question is whether there is selectivity in the connections between neurons and whether this may vary depending on the neuronal subtype. To address this, we analyzed the axonal arbors of individual neocortical ChCs, using a transgenic mouse line (Nkx2.1-Cre::Madm) in which the cell bodies of GFP + ChCs are detected in the layer $1 / 2$ border (Xu et al., 2008; Woodruff et al., 2009). This strain enabled us to identify scores of ChCs and analyze their morphologies systematically, something that has not been possible in previous studies, which relied on inconsistent and incomplete labeling of ChCs in Golgi stains or occasional electrode recordings from them (and subsequent HRP or biocytin fills) in vivo or in slice preparations (Somogyi, 1977; Fairén and Valverde, 1980; Somogyi et al., 1982; Li et al., 1992; Kawaguchi, 1995).

Our conclusions are restricted to this specific group of ChCs, in the border between layers 1 and 2. In this population of upper layer ChCs from somatosensory cortex, we examined the targeting of $\mathrm{ChC}$ cartridges on AISs by reconstructing their axons and using immunocytochemical methods to label their axonal targets. Our first conclusion is that practically all cartridges of a ChC contact an AIS. Thus, we confirm the original description by Somogyi (1977) of ChC as being axo-axonic. Although we observe axonal branches with boutons "en passant" and occasional isolated single axonal boutons that do not appear to belong to cartridges, we are not sure of their synaptic nature. Further ultrastructural study will be necessary to discern their targets.

\section{Overlapping ChC innervation of axon initial segments}

Our second conclusion relates to the number of boutons per $\mathrm{ChC}$ cartridge, three to five on average in our data. This is consistent with previous estimates for rodent somatosensory cortex, although cartridges in other cortical areas or species have more boutons (DeFelipe et al., 1985; Fariñas and DeFelipe, 1991; Inda et al., 2008). Ultrastructural reconstructions of AISs in the rodent neocortex have been performed only in infragranular layers of adult rats (Mendizabal-Zubiaga et al., 2007), showing that the average number of axo-axonic synaptic contacts on typical pyramidal AISs is 17.6 (range $15-22 ; n=5$ ). These numbers are very close to our estimates based on combined analyses of GFP + ChC cartridges, Ankyrin G (AIS), and VGAT (GABAergic synapses) immunoreactivity. With this approach, we find that each $\mathrm{ChC}$ on average has 4 boutons on an AIS, whereas each AIS has around 15 total putative synapses. Using these results, we estimate that an average of $\sim 4$ ChCs innervate each pyramidal neuron, generating a densely overlapping matrix of connectivity. In fact, since VGAT is present in most but not all GABAergic synapses (Chaudhry et al., 1998) (but see Wang and Sun, 2012), we might actually have underestimated the total number of synapses in our analyses. Thus, we conclude that there is convergent and overlapping innervation of pyramidal neurons by neocortical ChCs.

\section{Dense ChC innervation of local territories}

Our third conclusion is that the innervation of local pyramidal neurons by ChCs is dense. We examined the target selectivity of ChCs by analyzing the percentage of AISs innervated by a cartridge within the $\mathrm{ChC}$ arbor, and we find a relatively high percentage of innervation. Depending on how one defines the denominator of the percentage (maximum vs convex hull analysis), from 35 to $50 \%$ of all AISs within $210 \mu \mathrm{m}$ below the cell body were found to be contacted by a cartridge. Although already high, considering we are dealing with the connections generated by a single neuron, these percentages of innervation are likely to be underestimations for several reasons. First, our methods probably do not completely reveal the full extent of the ChC axon, either because the GFP immunolabeling in the ChC arbor may not be fully detectable or the histological processing may have lost some axonal branches or boutons. Second, our definition of ChC-AIS contact, which required at least two adjacent boutons 
to be present, may lead to an underestimation as single bouton contacts were excluded. Third, a significant underestimation could arise from our definition of the denominator of the percentage equation, since it is likely that, even with the restrictive convex hull criteria, we include pyramidal cells located too far from the $\mathrm{ChC}$ axon to realistically be able to be innervated by it. Finally, our AIS markers label AISs of all neurons including cortical interneurons (which could account for $15-20 \%$ of all the AISs), which are not targeted by ChCs. Taking all these factors into account, we expect that the true connectivity rates should be higher, and imagine that ChCs likely contact a large majority of their neighboring neurons that are within the immediate vicinity of their axonal branches. Indeed, we can observe areas where almost every single pyramidal cell is innervated ( 9 of 11 ; Fig. $3 A$, inset). This suggests a complete lack of innervation selectivity, and is also consistent with the matching of the spatial distribution of cartridges to the spatial distributions of AISs (Fig. $2 B, C$ ). On the other hand, there are territories with apparently little innervation, which could be explained by the mere lack of axonal branching in that area or, alternatively, due to specific avoidance of the axon to certain subregions. Reexamination of the $\mathrm{ChC}$ innervation with methods that could detect potential biases in target selection, perhaps by identifying different subpopulations of pyramidal cells, could discern between these possibilities.

\section{Developmental profile of $\mathrm{ChC}$ innervation}

Our fourth and final conclusion is that there are no large differences in the innervation pattern of pyramidal cells by $\mathrm{ChC}$ axons during the developmental period analyzed (P18-P90). Although in older ages $\mathrm{ChC}$ arbors expand laterally, the total number of cartridges increases, and there is a lower percentage of cartridges apposing an AIS, these changes are relatively small. Importantly, we failed to detect developmental differences in other anatomical properties of $\mathrm{ChC}$ axons, including the number of boutons, the distribution of cartridges and AISs and the percentage of AIS contacted (Fig. 5), indicating that the overall connectivity pattern remains the same from P18 to P90. These developmental similarities have interesting implications. First, as soon as the cartridges are clearly detectable, around P18 in our samples, they already target AISs. It is possible that $\mathrm{ChC}$ axon terminals could target any other subcellular location before they form cartridges, such as the pyramidal cell somata, similar to the basket cells of the cerebellum innervating the AIS of Purkinje cells (Ango et al., 2004). This could be examined in future studies with time-lapse imaging of the $\mathrm{ChC}$ arbor in cultures. Second, the distribution of cartridge-AIS appositions in the vertical and lateral extent of the neocortex does not change during the developmental period analyzed. Clusters of cartridges densely innervating AISs are observed at all ages analyzed. These findings suggest that the $\mathrm{ChC}$ axon terminal chooses its targets as early as the time it forms, and there is no obvious elimination of cartridges. On the other hand, elimination of ChCs themselves, or whether the $\mathrm{ChC}$ arbor undergoes dynamic elimination and addition of cartridges or not, cannot be ruled out. In any case, the net result is that the proportion of cartridge-AIS appositions remains constant throughout development with an overall increase in the arbor size.

\section{Comparison with other interneurons}

In summary, we find that ChCs innervate their local pyramidal neighbors very effectively. This innervation pattern is overall not only dense but, in addition, overlapping between different ChCs, as if the objective of the population of ChCs was to effectively innervate every single pyramidal neuron multiple times. It is interesting to put these findings in perspective with results from other interneuron subtypes. Indeed, the dense connectivity we document is consistent with recent studies that have examined the output connectivity of interneurons with different methods. Using optical and electrophysiological approaches, the connectivity of parvalbumin-positive interneurons (which also include ChCs but are mostly basket cells) was found to be very dense and unspecific (Packer and Yuste, 2011). A similar result was found in a study of the connections between somatostatin-expressing interneurons and pyramidal cells (Fino and Yuste, 2011). Finally, using a combination of electrophysiological and ultrastructural approaches, neurogliaform cells were reported to have a high number of synapses directly on the neuropil, as if they were releasing GABA extensively and affecting the neighboring pyramidal cells by volume transmission (Oláh et al., 2009). Together, these studies reveal a consistent picture for the functional effect of GABAergic innervation in the cortex, where each interneuron subtype appears to exert a wide and unspecific influence on its local neighbors. While it is clear that different subtypes of interneurons specifically target distinct subcellular compartments of the pyramidal cells (Buhl et al., 1994a), as illustrated also by our own results confirming the extreme specificity of the axo-axonic innervation of ChCs (Fig. 3B) (Somogyi, 1977), perhaps different interneuron subtypes exert a distinct functional influence on pyramidal cells, yet they treat all local pyramidal cells the same, as essentially equivalent, innervating them all.

\section{References}

Ango F, di Cristo G, Higashiyama H, Bennett V, Wu P, Huang ZJ (2004) Ankyrin-based subcellular gradient of neurofascin, an immunoglobulin family protein, directs GABAergic innervation at Purkinje axon initial segment. Cell 119:257-272. CrossRef Medline

Buhl EH, Halasy K, Somogyi P (1994a) Diverse sources of hippocampal unitary inhibitory postynaptic potentials and the number of synaptic release sites. Nature 368:823-828. CrossRef Medline

Buhl EH, Han ZS, Lörinczi Z, Stezhka VV, Karnup SV, Somogyi P (1994b) Physiological properties of anatomically identified axo-axonic cells in the rat hippocampus. J Neurophysiol 71:1289-1307. Medline

DeFelipe J (1999) Chandelier cells and epilepsy. Brain 122:1807-1822. CrossRef Medline

DeFelipe J, Hendry SH, Jones EG, Schmechel D (1985) Variability in the terminations of GABAergic chandelier cell axons on initial segments of pyramidal cell axons in the monkey sensory-motor cortex. J Comp Neurol 231:364-384. CrossRef Medline

Fairén A, Valverde F (1980) A specialized type of neuron in the visual cortex of cat: a Golgi and electron microscope study of chandelier cells. J Comp Neurol 194:761-779. CrossRef Medline

Fariñas I, DeFelipe J (1991) Patterns of synaptic input on corticocortical and corticothalamic cells in the cat visual cortex. II. The axon initial segment. J Comp Neurol 304:70-77. CrossRef Medline

Fazzari P, Paternain AV, Valiente M, Pla R, Luján R, Lloyd K, Lerma J, Marín O, Rico B (2010) Control of cortical GABA circuitry development by Nrg1 and ErbB4 signalling. Nature 464:1376-1380. CrossRef Medline

Fiala JC (2005) Reconstruct: a ad libitum editor for serial section microscopy. J Microsc 218:52-61. CrossRef Medline

Fino E, Yuste R (2011) Dense inhibitory connectivity in neocortex. Neuron 69:1188-1203. CrossRef Medline

Glickfeld LL, Roberts JD, Somogyi P, Scanziani M (2009) Interneurons hyperpolarize pyramidal cells along their entire somatodendritic axis. Nat Neurosci 12:21-23. CrossRef Medline

Howard A, Tamas G, Soltesz I (2005) Lighting the chandelier: new vistas for axo-axonic cells. Trends Neurosci 28:310-316. CrossRef Medline

Inda MC, Defelipe J, Muñoz A (2007) The distribution of chandelier cell axon terminals that express the GABA plasma membrane transporter GAT-1 in the human neocortex. Cereb Cortex 17:2060-2071. CrossRef Medline

Inda MC, DeFelipe J, Muñoz A (2008) Morphology and distribution of chandelier cell axon terminals in the mouse cerebral cortex and claustroamygdaloid complex. Cereb Cortex 19:41-54. CrossRef Medline 
Jones EG (1975) Varieties and distribution of non-pyramidal cells in the somatic sensory cortex of the squirrel monkey. J Comp Neurol 160:205267. CrossRef Medline

Kawaguchi Y (1995) Physiological subgroups of nonpyramidal cells with specific morphological characteristics in layer II/III of rat frontal cortex. J Neurosci 15:2638-2655. Medline

Klausberger T, Magill PJ, Márton LF, Roberts JD, Cobden PM, Buzsáki G, Somogyi P (2003) Brain-state- and cell-type-specific firing of hippocampal interneurons in vivo. Nature 421:844-848. CrossRef Medline

Krimer LS, Goldman-Rakic PS (2001) Prefrontal microcircuits: membrane properties and excitatory input of local, medium, and wide arbor interneurons. J Neurosci 21:3788-3796. Medline

Lewis DA, Anderson SA (1995) The functional architecture of the prefrontal cortex and schizophrenia. Psychol Med 25:887-894. CrossRef Medline

Li XG, Somogyi P, Tepper JM, Buzsáki G (1992) Axonal and dendritic arborization of an intracellularly labeled chandelier cell in the CA1 region of rat hippocampus. Exp Brain Res 90:519-525. Medline

Lund JS, Lewis DA (1993) Local circuit neurons of developing and mature macaque prefrontal cortex: Golgi and immunocytochemical characteristics. J Comp Neurol 328:282-312. CrossRef Medline

Martínez A, Lübke J, Del Río JA, Soriano E, Frotscher M (1996) Regional variability and postsynaptic targets of chandelier cells in the hippocampal formation of the rat. J Comp Neurol 376:28-44. CrossRef Medline

Mendizabal-Zubiaga JL, Reblet C, Bueno-Lopez JL (2007) The underside of the cerebral cortex: layer V/VI spiny inverted neurons. J Anat 211:223236. CrossRef Medline

Molnár G, Oláh S, Komlósi G, Füle M, Szabadics J, Varga C, Barzó P, Tamás G (2008) Complex events initiated by individual spikes in the human cerebral cortex. PLoS Biol 6:e222. CrossRef Medline

Oláh S, Füle M, Komlósi G, Varga C, Báldi R, Barzó P, Tamás G (2009) Regulation of cortical microcircuits by unitary GABA-mediated volume transmission. Nature 461:1278-1281. CrossRef Medline

Packer AM, Yuste R (2011) Dense, unspecific connectivity of neocortical parvalbumin-positive interneurons: a canonical microcircuit for inhibition? J Neurosci 31:13260-13271. CrossRef Medline

Somogyi P (1977) A specific "axo-axonal" interneuron in the visual cortex of the rat. Brain Res 136:345-350. CrossRef Medline
Somogyi P, Freund TF, Cowey A (1982) The axo-axonic interneuron in the cerebral cortex of the rat, cat and monkey. Neuroscience 7:25772607. CrossRef Medline

Somogyi P, Freund TF, Hodgson AJ, Somogyi J, Beroukas D, Chubb IW (1985) Identified axo-axonic cells are immunoreactive for GABA in the hippocampus and visual cortex of the cat. Brain Res 332:143-149. CrossRef Medline

Szabadics J, Varga C, Molnár G, Oláh S, Barzó P, Tamás G (2006) Excitatory effect of GABAergic axo-axonic cells in cortical microcircuits. Science 311:233-235. CrossRef Medline

Szentágothai J (1975) The "module-concept" in cerebral cortex architecture. Brain Res 95:475-496. CrossRef Medline

Tamás G, Szabadics J (2004) Summation of unitary IPSPs elicited by identified axo-axonic interneurons. Cereb Cortex 14:823-826. CrossRef Medline

Taniguchi H, Lu J, Huang ZJ (2013) The spatial and temporal origin of chandelier cells in mouse neocortex. Science 339:70-74. CrossRef Medline

Wang X, Sun QQ (2012) Characterization of axo-axonic synapses in the piriform cortex of Mus musculus. J Comp Neurol 520:832-847. CrossRef Medline

Woodruff A, Xu Q, Anderson SA, Yuste R (2009) Depolarizing effect of neocortical chandelier neurons. Front Neural Circuits 3:15. CrossRef Medline

Woodruff AR, Anderson SA, Yuste R (2010) The enigmatic function of chandelier cells. Front Neurosci 4:201. CrossRef Medline

Woodruff AR, McGarry LM, Vogels TP, Inan M, Anderson SA, Yuste R (2011) State-dependent function of neocortical chandelier cells. J Neurosci 31:17872-17886. CrossRef Medline

Xu Q, Tam M, Anderson SA (2008) Fate mapping Nkx2.1-lineage cells in the mouse telencephalon. J Comp Neurol 506:16-29. CrossRef Medline

Xu X, Callaway EM (2009) Laminar specificity of functional input to distinct types of inhibitory cortical neurons. J Neurosci 29:70-85. CrossRef Medline

Zaitsev AV, Povysheva NV, Gonzalez-Burgos G, Rotaru D, Fish KN, Krimer LS, Lewis DA (2009) Interneuron diversity in layers 2-3 of monkey prefrontal cortex. Cerebral cortex 19:1597-1615. CrossRef Medline 